\title{
CONSUMER CREATIVITY AND THE WORLD'S BIGGEST BRAND
}

Karen Robson, Simon Fraser University, Canada

Kirk Plangger, Simon Fraser University, Canada

Adam Mills, Simon Fraser University, Canada

\begin{abstract}
Consumers are creative with the products and services they use. But all these consumer innovations are not equal in terms of creativity. This paper examines 51 consumer generated uses for Coca-Cola using two creativity dimensions: novelty and utility. Using these dimensions, we propose a consumer creativity typology, which includes: low value uses, marketed uses, unusual uses, and potentially marketed uses. Implications, risks, and opportunities are discussed for how a firm may respond to creative consumers based on how creative is their innovation.
\end{abstract}

References available upon request 